\title{
IMPLANTAÇÃO DA REFORMA PSIQUIÁTRICA NO MUNICÍPIO DE VOLTA REDONDA: IMPLICAÇÕES PARA A ENFERMAGEM
}

\author{
Ana Emília Cardoso Moraes ${ }^{1}$, Antonio José de Almeida Filho², Tânia Cristina Franco Santos ${ }^{3}$, Maria Angélica \\ de Almeida Peres ${ }^{4}$, Maria Cristina Frères de Souza ${ }^{5}$, Alexandre Barbosa de Oliveira ${ }^{6}$
}

\footnotetext{
${ }^{1}$ Mestre em Enfermagem. Enfermeira da Secretaria Municipal de Saúde do município de Volta Redonda. Rio de Janeiro, Brasil. E-mail: anaemiliacardoso@bol.com.br

2 Doutor em Enfermagem. Professor Adjunto do Departamento de Enfermagem Fundamental da Escola de Enfermagem Anna Nery (EEAN) da Universidade Federal do Rio de Janeiro (UFRJ). Rio de Janeiro, Brasil E-mail: ajafilho@terra.com.br

${ }^{3}$ Doutora em Enfermagem. Professora Associado do Departamento de Enfermagem Fundamental EEAN/UFRJ. Rio de Janeiro, Brasil. E-mail: taniacristinafsc@terra.com.br

${ }^{4}$ Doutora em Enfermagem. Professora Adjunto do Departamento de Enfermagem Fundamental da EEAN/UFRJ. Rio de Janeiro, Brasil E-mail: aguaonda@uol.com.br.

${ }^{5}$ Doutoranda do Programa de Pós-graduação em Enfermagem da EEAN/UFRJ. Enfermeira do Instituto Nacional de Câncer. Rio de Janeiro, Brasil E-mail: crisfrer@oi.com.br

${ }^{6}$ Doutorando do Programa de Pós-graduação em Enfermagem da EEAN/UFRJ. Rio de Janeiro, Brasil E-mail:alexbaroli@yahoo. com.br
}

RESUMO: O estudo teve como objeto a intervenção na Casa de Saúde Volta Redonda e suas implicações para a enfermagem psiquiátrica. As fontes históricas estão constituídas de documentos escritos e orais. Os dados foram organizados, classificados e analisados, conforme o método histórico, com o apoio dos conceitos de habitus e campo de Pierre Bourdieu e da literatura sobre a Reforma Psiquiátrica no Brasil. As mudanças na política de Saúde Mental exigiram novas práticas e atitudes consoantes com o processo de implantação da Reforma Psiquiátrica naquele município, tendo como pilar a inserção do paciente psiquiátrico na comunidade e o resgate de sua cidadania. Estas medidas faziam parte de um projeto político partidário mais abrangente, com experiências acumuladas em outros municípios brasileiros. A enfermagem conquistou espaços de poder e visibilidade capazes de assegurar sua participação em diferentes espaçõs decisórios no campo da assitência psiquiátrica no município.

DESCRITORES: Enfermagem. História da enfermagem. Enfermagem psiquiátrica.

\section{IMPLEMENTATION OF PSYCHIATRIC REFORM IN THE CITY OF VOLTA REDONDA, BRAZIL: IMPLICATIONS FOR NURSING}

\begin{abstract}
The object of this was intervention in the Brazilian Assisted Living Home Casa de Saúde Volta Redonda and their implications for psychiatric nursing. The historical sources are constituted of written and oral documents. The data was organized, categorized, and analyzed according to the historical method, with the support from habitus concepts and the field of Pierre Bourdieu, as well as literature on Brazilian psychiatric reform. The changes in Mental Health policies have required new practices and attitudes consonant with the psychiatric reform implementation process in that municipality, based on the pillar of inserting the psychiatric patient back into the community and reclaiming their citizenship. These measures were part of a broader partisan political project, with accumulated experience in other Brazilian municipalities. Nursing gained positions of power and visibility, able to ensure their participation in different decision-making arenas in the local field of psychiatric assistance.
\end{abstract}

DESCRIPTORS: Nursing. History of nursing. Psychiatric nursing

\section{IMPLEMENTACIÓN DE LA REFORMA PSIQUIÁTRICA EN EL MUNICIPIO DE VOLTA REDONDA, BRAZIL: IMPLICACIONES PARA LA ENFERMERÍA}

RESUMEN: Este estudio tuvo como objetivo la intervención en la Casa de Saúde Volta Redonda y sus implicaciones para la enfermería psiquiátrica. Las fuentes históricas son documentos escritos y orales. La organización, clasificación y análisis de los datos se hizo según el método histórico, con el apoyo de los conceptos de habitus y campo de Pierre Bourdieu y de la bibliografía sobre la reforma psiquiátrica en Brasil. Los cambios en la política de salud mental exigieron nuevas prácticas y actitudes de acuerdo con el proceso de implementación de la reforma psiquiátrica en aquel municipio, cuyo pilar es la inserción del enfermo psiquiátrico en la comunidad y el rescate de su ciudadanía. Estas medidas forman parte de un proyecto político partidario más amplio, con experiencias en otros municipios brasileños. La Enfermería ha ganado posiciones de poder y visibilidad para asegurar su participación en diferentes espacios decisorios en el ámbito de la asistencia psiquiátrica en el municipio.

DESCRIPTORES: Enfermería. Historia de la enfermería. Enfermería psiquiátrica. 


\section{INTRODUÇÃO}

A Reforma Psiquiátrica brasileira, iniciada na década de 1980, implementou novas propostas e possibilidades de assistência ao cliente com sofrimento psíquico, assegurando o exercício de seu direito a cidadania. ${ }^{1}$ A reorganização do modelo de assistência psiquiátrica no Brasil se deu através de um processo de desospitalização do doente mental e criação de uma rede de suporte assistencial extra-hospitalar, voltada para o atendimento ambulatorial, quais sejam: os Hospitais-Dia e os Centros de Atenção Psicossocial (CAPS), que visavam oferecer ao paciente psiquiátrico opção de cuidados distintos do modelo manicomial. ${ }^{2-3}$

Tal reformulação da assistência exigiu uma mudança na prática do cuidado psiquiátrico levando a reformulação da relação terapêutica entre paciente-profissional e paciente-instituição. ${ }^{4}$ No que tange a enfermagem, esta ainda mantêm algumas práticas tradicionais - triagem e controle principalmente medicamentoso dos pacientes em crise - embora o discurso aponte para atividades de relacionamento interpessoal e trabalho interdisciplinar. Assim, embora reconheçam a limitação daquele modelo médico psiquiátrico na abordagem do sujeito com transtornos mentais, ocupamse, rotineiramente, de sua "doença mental" em controlar o comportamento dos usuários pautado pelo modelo organicista, ou seja, não atuam como agentes de transformação dessa realidade. ${ }^{3}$

Estudos históricos mostram que a Reforma Psiquiátrica vem ocorrendo de forma lenta e gradual, mesmo quando implicações éticas e legais evidenciam a necessidade de aceleração deste processo. Um dos desafios que se destaca no campo psiquiátrico é a busca de novos caminhos pela enfermagem psiquiátrica em que se possa reorganizar o cuidado a partir de uma visão ampliada da assistência psiquiátrica, indo de encontro ao modelo biologicista/organicista, que se mostrou insuficiente para dar conta das questões complexas que envolvem este campo na atualidade.

A prática da enfermagem, no bojo da Reforma Psiquiátrica, tem exigido maior percepção das necessidades do paciente, tendo o enfermeiro que desenvolver habilidades que lhe possam conferir maior competência para melhor desempenho de suas funções, com educação contínua, principalmente no que se refere à cooperação interdisciplinar, com foco no cuidado que visa $o$ atendimento do paciente em todas as suas dimensões, incluindo o resgate da cidadania como prioridade nas ações de saúde.
Em Volta Redonda, a proposta de reformulação da assistência psiquiátrica teve início em 1993, por ocasião da implantação da Reforma Sanitária naquele município, onde, ao avaliar a situação dos serviços de saúde oferecidos a população, observou-se que não havia oferta de serviço psiquiátrico extra-hospitalar. Além disso, as duas instituições psiquiátricas do município eram a Clínica Santo Antônio e a Casa de Saúde Volta Redonda (CSVR), ambas as instituições privadas, conveniadas com o Sistema Único de Saúde (SUS). Sendo assim, no mesmo ano de 1993, foi aprovada a Portaria do MS $n^{\circ} 88$, que impunha a reorganização da assistência hospitalar psiquiátrica em Volta Redonda.

As instituições psiquiátricas de Volta Redonda prestavam uma assistência caracterizada pelo confinamento e contenção do doente mental e atendiam, além da população do próprio município, também a população de municípios vizinhos, como Barra do Piraí, Piraí, Barra Mansa e Pinheiral, entre outros. A situação precária de funcionamento desses estabelecimentos foi registrada após sindicância da Secretaria de Saúde, colocando-os sob ameaça de fechamento pelo descumprimento das normas previstas na Portaria do MS $n^{\circ} 88 / 93$. Sendo assim, o governo municipal inicia um movimento para viabilizar a adequação dessas instituições a nova lei de saúde mental. Nesse processo, evidenciou-se que além da oferta de um modelo assistencial excludente, outra dificuldade que se apresentava era a crise financeira vivenciada pelas duas instituições. Diante disso, os desdobramentos foram o fechamento da Clínica Santo Antônio por decisão do seu proprietário, em fevereiro de 1994, e a proposta vinda do diretor da CSVR de se estabelecer uma co-gestão entre este estabelecimento e o município. ${ }^{5}$

No entanto, o poder público foi contrário a tal proposta, uma vez que a CSVR não apresentava recursos financeiros e optou por realizar a intervenção da mesma em abril de 1994, como estratégia para garantir a assistência de saúde mental no município. Na opinião do Coordenador do Programa de Saúde Mental e da diretora técnica da CSVR, a época, a intervenção não tinha apenas o objetivo de garantir o atendimento à população, mas também o de assumir o compromisso de transformar a assistência prestada, constituindo o hospital como um espaço de transição na direção à construção de uma rede de saúde mental. ${ }^{5}$

Assim, diante da problemática apresentada, o presente estudo tem como objeto a intervenção na Casa de Saúde Volta Redonda (CSVR) e suas 
implicações para a enfermagem psiquiátrica, no período de 1994 a 1995. Foram elaborados os seguintes objetivos: descrever as repercussões na assistência de enfermagem da Casa de Saúde Volta Redonda a partir da intervenção do poder público municipal; e analisar a participação do enfermeiro na implantação do novo modelo assistencial psiquiátrico no município de Volta Redonda.

\section{METODOLOGIA}

Trata-se de uma pesquisa de cunho históricosocial, pois compreende o estudo dos grupos humanos no seu espaço temporal com a preocupação de discutir os diferentes aspectos que envolvem o cotidiano das diferentes classes e grupos sociais. A pesquisa histórico-social é, portanto, entendida como síntese e permite a reafirmação do princípio de que, em história, todas as abordagens estão inscritas no social e se interligam, e ainda possibilitam delimitar um campo específico de problemas a serem formulados à disciplina histórica. ${ }^{6}$

As fontes primárias escritas foram localizadas no Centro de Estudos de Saúde Mental da CSVR, na prefeitura Municipal de Volta Redonda e nos acervos pessoais de Elydio Vasconcellos e Paulo Zambrone, psicólogos que participaram do processo de implantação da Reforma Psiquiátrica naquele município. Estão constituídas de documentos escritos, tais como ofícios, relatórios, leis, decretos, portarias e nomeações.

Outras fontes primárias foram os depoimentos orais de pessoas envolvidas, dentre os quais: do Prefeito, à época da intervenção; da Secretária Municipal de Saúde; da Interventora da CSVR, nomeada pela Secretária Municipal de Saúde; da Enfermeira contratada após a intervenção e que assumiu a coordenação de enfermagem da CSVR; e de uma Auxiliar de Enfermagem que trabalhava na CSVR antes da intervenção e que permaneceu na instituição após a intervenção. $\mathrm{O}$ depoimento escrito também constituiu o acervo de fontes primárias, em função da dificuldade de acesso, para obter a versão da enfermeira, coordenadora do primeiro dispositivo extra-hospitalar do município de Volta Redonda, pois a mesma era coordenadora do curso de graduação em enfermagem da Universidade de Barra Mansa (UBM) e encontrava-se naquele momento com dificuldades de tempo para ser entrevistada, assim foi-lhe sugerido a possibilidade de obter o depoimento escrito.

Utilizou-se como critério de seleção de documentos escritos, aqueles referentes ao processo de intervenção do serviço de saúde mental do município de Volta Redonda, bem como as fontes oficiais que definiam diretrizes para a reforma psiquiátrica. Os sujeitos foram selecionados em função da participação direta destes no processo de implantação da Reforma Psiquiátrica naquele município.

A coleta de dados, ou seja, de fontes primárias, ocorreu no período de 13 de outubro de 2007 a 08 de setembro de 2008, e foi realizada com autorização escrita da Secretaria Municipal de Saúde de Volta Redonda, na pessoa da Secretária Municipal de Saúde, do Programa de Saúde Mental (PSM) de Volta Redonda, através do Coordenador desse programa e do diretor da Casa de Saúde Volta Redonda.

Os achados foram classificados, contextualizados e interpretados à luz da literatura sobre a reforma psiquiátrica e a assistência ao doente mental, o que permitiu a construção de uma versão original sobre a atuação do enfermeiro em um cenário especializado. Além disso, o respaldo teórico dos conceitos de habitus e campo do sociólogo francês Pierre Bourdieu, evidenciou que a aquisição de capital cultural sobre assistência ao doente mental, pelos enfermeiros, consoante com as mudanças no campo da psiquiatria, conferiu poder aos detentores desse capital para enunciar o discurso autorizado sobre a assistência de enfermagem em acordo com o novo paradigma, isso porque os indivíduos ou grupos ocupam posições no campo que dependem do capital acumulado. Por isso mesmo, a aplicação do conceito de $h a-$ bitus se justifica pelo entendimento deste como uma disposição incorporada que funciona como princípio gerador do que fazemos ou das respostas que damos à realidade social. O conceito de campo subsidiou a compreensão da CSVR como espaço de trocas sociais entre os sujeitos envolvidos com o processo de transição da nova proposta de assistência psiquiátrica no município de Volta Redonda.

A apresentação de excertos dos depoimentos foi identificada com a letra " $\mathrm{D}$ ", seguida do número correspondente a sequência no texto. Desta forma, o depoimento da Enfermeira contratada, que assumiu a coordenação de enfermagem da CSVR está indicado com D1; o da Auxiliar de Enfermagem, com D2; o da Secretária Municipal de Saúde, D3; o da Interventora da CSVR, D4; e do prefeito, à época, com D5; e o da enfermeira coordenadora do primeiro CAPS, com D6.

As fontes secundárias, literatura que subsidiam a análise dos dados coletados, abordaram 
a reforma psiquiátrica, suas implicações para enfermagem e a sociedade, e os estudos de história da enfermagem. Essas fontes foram compostas de artigos, dissertações e livros, localizadas no Centro de Estudos de Saúde Mental da CSVR (CESAM), na Biblioteca Setorial da pós-graduação da Escola de Enfermagem Anna Nery/UFRJ e nos arquivos do Programa de Saúde Mental do município de Volta Redonda.

Este estudo acrescenta às pesquisas sobre a temática, o registro de um movimento de reforma psiquiátrica a partir da intervenção das autoridades municipais na rede privada de assistência à saúde mental daquele município. Ademais, tal intervenção notabilizou-se pelo uso de uma clínica psiquiátrica, a CSVR, como lócus do processo de implantação da reforma psiquiátrica em Volta Redonda, a medida que se investia na formação de uma rede de apoio para o atendimento dos usuários com sofrimento mental. Com isso, várias alterações tiveram que ser adotadas no âmbito da CSVR para que a mesma não reproduzisse o atendimento até então observado na instituição.

Cabe ressaltar que, em cumprimento da Resolução 196/96 do Conselho Nacional de Saúde, o presente estudo foi submetido, em 25 de setembro de 2007 ao Comitê de Ética em Pesquisa da Escola de Enfermagem Anna Nery/ Hospital Escola São Francisco de Assis, com o número de protocolo 079/07, sendo o mesmo aprovado. Os sujeitos da pesquisa assinaram o termo de consentimento livre e esclarecido, onde se explicitava a impossibilidade de assegurar o anonimato, uma vez que ocupavam cargos públicos. Também autorizaram a gravação dos depoimentos e a cessão de direitos das entrevistas no todo ou em parte para citação e utilização dos mesmos para fins de publicações.

\section{Repercussões da intervenção do poder pú- blico municipal no modelo assistencial da Casa de Saúde de Volta Redonda}

O grupo interventor era formado pelo Prefeito Municipal de Volta Redonda, Maria a Secretária Municipal de Saúde, o Coordenador do Programa de Saúde Mental e uma Assistente Social. Cabe ressaltar que este grupo foi o mesmo que liderou o processo de implantação da Reforma Psiquiátrica em Volta Redonda. Portanto, a constituição do grupo interventor, formado por figuras prestigiosas do campo da psiquiatria e da sociedade em geral, evidenciou a eficácia de sua representação, particularmente por sua autoridade profissional e científica, no sentido de enunciar o discurso autorizado sobre a assistência psiquiátrica e, por conseguinte, fazer a ordem social, impondo teorias e práticas relativas ao novo modelo assistencial.

O primeiro movimento do grupo interventor foi o de reorganizar o processo de internação do doente mental, tendo como foco o próprio ato de internar e a assistência prestada antes, durante e após este processo.

Assim, no momento em que ocorreu a intervenção da CSVR, o atendimento prestado tinha como foco a internação hospitalar. A equipe de enfermagem era composta por: um enfermeiro, um técnico de enfermagem, um auxiliar de enfermagem e 10 atendentes de enfermagem, sendo estes últimos, sem a devida qualificação profissional, pois se tratavam de profissionais aproveitados do contingente dos serviços de limpeza e da copa, os quais eram promovidos a atendentes de enfermagem, por serem profissionais da confiança do administrador. Ademais, o modelo psiquiátrico tradicional vigente, que era voltado para administração de medicamentos, alimentação e contenção dos doentes, cujos vínculos familiares e sociais foram rompidos pela hospitalização prolongada, não se coadunava com os preceitos da reforma psiquiátrica. ${ }^{5}$

Uma das estratégias da equipe interventora foi a mobilização e o comprometimento da equipe de saúde, dos pacientes e de suas famílias com a reforma assistencial, considerando que a mesma não se restringia somente aos aspectos psiquiátricos, mas também ao contexto social dos envolvidos. ${ }^{5}$ Nesse sentido, as alianças com a equipe de saúde foram importantes porque qualquer tentativa de instituir uma nova ordem, em geral, conta com a resistência daqueles ocupantes de posições dominantes no espaço em questão e que são também os maiores interessados na perpetuação de suas posições de poder.

Ademais, havia a necessidade de integração da equipe de saúde em busca de um trabalho interdisciplinar. Esse trabalho comportava a troca de saberes entre as diversas áreas de conhecimento.? No caso específico da CSVR, a equipe de enfermagem necessitava compreender as concepções defendidas pela Reforma Psiquiátrica e partir daí, aplicá-las na assistência de enfermagem. Cabe ressaltar que, ainda hoje a enfermagem apresenta dificuldades em desenvolver plenamente as atividades que não sejam àquelas realizadas no hospital psiquiátrico. ${ }^{8}$ 
Outra iniciativa importante que fez parte das estratégias de aperfeiçoamento dos profissionais da equipe interdisciplinar da CSVR foi à criação em 30 de junho de 1994 do Centro de Estudos em Saúde Mental de Volta Redonda (CESAM), sediado na CSVR. A criação de um espaço destinado a estudos na CSRV ao tempo em que oportunizou a difusão dos saberes inerentes à assistência psiquiátrica também contribuiu para que o grupo aderisse à nova proposta, pois o espaço contribui para formar o habitus, uma vez que a posse do capital cultural permite a apropriação de bens simbólicos, que conferem poder e prestígio nos diferentes espaços sociais. Ademais, o espaço habitado (ou apropriado), representado pelo Centro de Estudos, funciona como uma espécie de simbolização espontânea do espaço social, pois a posição dos indivíduos ou grupos no espaço social se expressa no espaço físico em que está situado.9-10

Assim, a Casa de Saúde Volta Redonda, naquele momento, investia na capacitação de recursos humanos, acreditando ser os profissionais, agente principal para a possibilidade de mudanças da assistência em Saúde Mental, e portando, agindo como agente difusor de um discurso, perfeitamente afinado com a proposta idealizada pelas autoridades municipais, as quais justificavam, reiteradamente, que os princípios da política de saúde mental fundavam-se no ideal da Reforma Psiquiátrica.

$\mathrm{Na}$ avaliação do grupo interventor que assumia o processo de implantação da Reforma Psiquiátrica e da equipe interdisciplinar formada, tal proposta permitiria eliminar as dificuldades dos pacientes relativas às questões da marginalidade e da exclusão social. As novas e diferentes relações que se desenhavam, pautadas na construção da cidadania, trouxeram questões e problemas estranhos ao modelo clínico: necessidades de moradia, afeto, espaços e transformação das relações familiares- que demandavam a necessidade de encontrar novas estratégias de ressocialização. ${ }^{5}$ Não obstante, ao mesmo tempo em que se queria desmontar o manicômio, se teciam os vínculos entre os problemas da loucura e os da vida cotidiana, aproximando-se em movimento, loucura e existência, exclusão e liberdade. ${ }^{11}$

Apesar das dificuldades, a equipe de interventores prosseguiu com a reforma assistencial da CSVR, buscando o permanente comprometimento da equipe. Assim, foi criado o colegiado de gerência, grupo composto pelos funcionários que tinham função de coordenação dos setores.
Nesse fórum eram discutidos os problemas do hospital e elaboradas, conjuntamente, as propostas de resolução.

Os interventores municipais se apresentavam como um grupo político comprometido com a implantação de uma proposta de uma assistência psiquiátrica que assegurasse o princípio da dignidade e de solidariedade humanas. Se por um lado a proposta mobilizava a equipe de enfermagem a se engajar nas novas práticas, por outro, despertava inúmeros receios, pois determinavam mudanças na prática predominante até então.

No depoimento oral da primeira enfermeira contratada após a intervenção municipal, observamos a dificuldade da equipe de enfermagem e, em especial, da chefe de enfermagem da CSVR, até aquele momento, em entender a nova proposta de trabalho, conforme relato: Para ela [enfermeira] estava sendo muito difícil aceitar a retirada das grades, e aceitar as novas mudanças. Abrirem as portas do hospicio e deixar os pacientes saírem. Tinham uma cultura na CSVR de manterem os pacientes fechados, enclausurados. O louco tinha que ficar fechado. A chava a intervenção [da CSVR] uma bobagem. Acreditavam que retirarem as grades ia fazer com que os pacientes ficassem mais agressivos (D1).

Um dos temas de particular relevância naquele momento foi o da periculosidade; muitas vezes os profissionais expressavam sua insegurança em relação aos pacientes "soltos". As discussões de equipe problematizavam a questão da violência objetivando um consenso ético, fundamental em toda intervenção profissional.

No que se refere à condição de agressividade dos doentes internados na CSVR, a enfermeira descreveu sua experiência como se segue: [...] com a abertura das enfermarias e permissão dos pacientes ao pátio foi verificado o contrário do que se pensava anteriormente, ou seja, que os pacientes ficariam agressivos e incontroláveis. A grade [exclusão] acabava excitando o paciente [...] (D1).

Os profissionais de enfermagem de nível médio e elementar, responsáveis pela assistência direta de enfermagem aos doentes hospitalizados (preparo e administração de medicações, banho, troca de roupa de cama, contenção no leito, registros de enfermagem, liberação dos usuários ao pátio no horário de visitas) também expressaram seus medos e incertezas ao novo, questionando como os pacientes confinados em instituições hospitalares por várias décadas se "comportariam soltos". No entanto, o excerto do depoimento de um auxiliar de enfermagem também pontua as 
consequências do confinamento do paciente no espaço hospitalar: quando os pacientes internavam, ele somente tinha visita depois de decorridos quinze dias, as quintas e domingos. Apenas duas vezes na semana, e não sei explicar porque os pacientes ficavam quinze dias sem visita alguma, só isolados. Não tinha direito de ir ao pátio. As mulheres tinham o pátio interno, aí elas ficavam naquele espaço. Mas os homens ficavam todos trancados lá dentro [da enfermaria], aquilo era de sofrer. Eram muitos conflitos lá dentro, uma confusão. Muita gente agitada. Não era fácil não! (D2).

Outro trecho de depoimento registra a participação ativa da equipe de enfermagem na contenção do paciente, bem como seu poder decisório em relação a essa conduta: tinha quarto - forte, grades, tudo era gradeado, igual a uma cadeia. As portas dos quartos fortes eram pesadas. Os pacientes podiam chutar que a porta não abria. Era uma espécie de castigo. Se o paciente estivesse muito agitado iria para o quarto - forte, deixava-o lá, sem nenhum critério. A porta era trancada com um cadeado grande, pelo lado de fora e era a enfermagem quem realizava tal procedimento, sem nenhuma autorização de outro profissional. A decisão era da enfermagem. Após, chamávamos o médico por telefone. O médico respaldava aquele tipo de conduta da enfermagem. Algumas vezes escreviam no prontuário, outras não. A contenção física também era uma prática comum, também realizada pela equipe de enfermagem (D2).

Assim, os obstáculos impostos à reconfiguração da assistência na CSVR se pautavam em oposições e resistências da equipe de enfermagem, antes calcada em um modelo tradicional que preconizava a exclusão dos doentes mentais da sociedade. Não obstante, esses profissionais que atuavam de maneira direta com os pacientes reconheciam os benefícios da nova proposta assistencial.

\section{A Enfermagem e a (re) novação da Casa de Saúde Volta Redonda}

Em face de dificuldades inerentes a incorporação da Reforma Psiquiátrica na CSVR por parte de alguns integrantes da equipe de enfermagem, a equipe interventora investiu na contratação de recursos humanos, uma vez que a equipe de enfermagem foi considerada insuficiente quantitativamente. Além disso, não possuíam a qualificação requerida para implantar a reforma em sua totalidade

A concretização da proposta de implantação da Reforma Psiquiátrica, em Volta Redonda, no Programa de Saúde Mental iniciado com a intervenção na CSVR se dá com a criação do primeiro dispositivo de assistência psiquiátrica extra-hospitalar, criado pelo Programa de Saúde Mental do município de Volta Redonda, que foi o Centro de Atenção Psicossocial (CAPS), inaugurado em 27 de setembro de 1995, e denominado "Usina de Sonhos". Este tinha capacidade de atendimento para até 40 pacientes por turno, funcionava anexo à CSVR, para dar continuidade ao tratamento aos egressos desse estabelecimento. ${ }^{5}$

Nesse contexto, a participação da enfermagem enquanto membro da equipe interdisciplinar demonstrava, aos profissionais de outras áreas, saberes específicos que a enfermagem detinha como ferramenta de trabalho, conquistando assim, visibilidade dentro da equipe, uma vez que os profissionais só conseguem participar do "jogo" específico de cada campo se dotados de um mínimo de capital específico; os campos, por onde os circulam os profissioanis, levados pela necessidade de estar no jogo social, são os locus onde operam e se alteram os habitus em conseqüência da mobilização de tipos diferentes de capital. ${ }^{9}$

Tanto assim que, a Secretária de Saúde, à época, expressou seu reconhecimento sobre a importância da equipe de enfermagem para a reorganização do serviço de assistência em saúde mental em Volta Redonda, com a seguinte afirmação: [...] a enfermagem era o pilar mais importante dentro do sistema de saúde [...] (D3).

Portanto, o reconhecimento da importância do capital profissional e científico do enfermeiro nas questões relativas ao novo modelo de assistência psiquiátrica representou uma espécie particular de capital simbólico, o qual simbolizava o reconhecimento (ou crédito) atribuído pelo conjunto de pares ou concorrentes. ${ }^{10}$

O prefeito ao considerar a importância da Reforma Psiquiátrica para Volta Redonda, também reconheceu a importância da enfermagem nesse processo: acho que foi uma das coisas mais importantes que aconteceram na saúde pública de Volta Redonda, naquele período. Parabéns a enfermagem! Foi uma mudança de paradigma e isso poucas vezes acontece no serviço público e aconteceu através da enfermagem. Parabéns a enfermagem! (D5).

Esse reconhecimento, por ser expresso por uma figura prestigiosa da sociedade da época, conferiu visibilidade e prestigio a enfermagem, pois, o discurso do prefeito tinha forte expressão à medida que era enunciado por um porta-voz dotado de poder de falar e de agir em nome de um grupo, falando pela magia da palavra de ordem, ou seja, era nomeado para essa missão por ser considerado 
autoridade máxima municipal. Representava o grupo tal como se obtivesse uma procuração, que lhe permitia agir e falar em nome desse grupo, de "se tomar pelo grupo" que ele encarnava, e de se identificar com aquela função atribuída. ${ }^{9}$

Com base no artigo 15 da Lei $n^{0} 7498 / 86$, que trata do exercício profissional da enfermagem, as atividades de técnicos e de auxiliares de enfermagem somente podem ser desempenhadas sob orientação e supervisão do enfermeiro. Nesse sentido, foram contratados, em 1994 para a CSVR, oito enfermeiros, quatro técnicos de enfermagem e 24 auxiliares de enfermagem, pois, da forma como se encontrava, era mantida uma condição de irregularidade na assistência de enfermagem naquela instituição, quando contava com apenas uma enfermeira.

De acordo com o novo modelo assistencial, o chefe de enfermagem deveria incorporar, como esperado, novas responsabilidades e compromissos inerentes ao cargo. Diante disso destaca-se a importância da figura do enfermeiro chefe, a quem caberia implantar uma dinâmica que viabilizasse o trabalho em equipe e promovesse a reestruturação do ambiente, de modo a eliminar as características asilares. Desta forma, ressalta-se que "a atuação do líder, neste caso, o enfermeiro, que poderá detectar os problemas vivenciados pela sua equipe, tem como objetivos: a oferta de treinamento necessário, desenvolvimento de criatividade, determinação e responsabilidade para a obtenção de uma assistência de qualidade ao paciente psiquiátrico". 12:732

Outro desafio que se apresentou à equipe interventora foi a desconstrução do imaginário coletivo sobre a importância daquele hospital junto à sociedade, uma vez que internação do doente mental em Volta Redonda era vista como importante medida de segurança para a sociedade. Em contrapartida, era necessário desenvolver uma rede de assistência extra-hospitalar que pudesse assegurar melhores condições de assistência ao doente psiquiátrico, tais como: atendimento de emergência nas 24hs no Centro de Atenção Intermediária em Saúde (CAIS); leitos clínicos em hospital geral, e criação de outras CAPS.

Segundo a Interventora nomeada pela Secretária Municipal de Saúde, a enfermagem participava não só do processo de assistência da equipe interdisciplinar, como também do processo decisório da Casa de Saúde Volta Redonda. Além disso, era importante na relação com os familiares dos doentes com a comunidade em geral. A interventora acrescenta que alguns profissionais $d a$ enfermagem tiveram tamanha identificação com a nova proposta de assistência que foram selecionados para serem alocados no CAPS "Usina de Sonhos" (D4). O significado dessa unidade era imenso por tratar-se da primeira unidade extra-hospitalar de atendimento ao doente psiquiátrico criada no município de Volta Redonda.

Para melhor instrumentalizar a enfermagem, a equipe interventora proporcionou vários cursos, treinamentos e palestras através do Centro de Estudos de Saúde Mental (CESAM), oportunizando a estes profissionais conhecer os fundamentos da Reforma Psiquiátrica. A nova responsabilização pelos cuidados de enfermagem a serem prestados com qualidade exigia atuação em várias frentes. A equipe de enfermagem teve também a oportunidade de participar de fóruns de decisão do colegiado de gerência da CSVR; de decisões nos projetos terapêuticos dos usuários, entre outros, o que demonstrava reconhecimento de sua competência profissional, junto à equipe de saúde, no campo da assistência psiquiátrica, portanto, o capital científico acumulado pelos enfermeiros se refletiu na conquista de autoridade profissional para se pronunciar nas questões relativas à enfermagem psiquiátrica na CSVR. ${ }^{10}$

A CSVR através da equipe interventora nomeou uma enfermeira para o cargo de direção administrativa, o que demonstrou confiança na capacidade do profissional de enfermagem para gerir o hospital. A enfermeira recebeu capacitação na Fundação Oswaldo Cruz (FIOCRUZ), com especialização em Gestão Hospitalar, sendo este oferecido somente para diretores de hospitais públicos, proporcionando a ela aumentar seu capital cultural para melhor instrumentalizá-la em suas atividades, pois, para exercer liderança e autoridade em seu trabalho, os enfermeiros precisam adquirir conhecimentos e desenvolver estratégia sobre os cuidados dispensados aos pacientes, além de reforçar e expandir a contribuição da enfermagem psiquiátrica para o sistema de saúde como um todo. ${ }^{12}$

Tendo como proposta o início da construção de uma rede de cuidados que pudesse substituir o modelo centrado no hospital psiquiátrico, o CAPS representava o avanço em direção ao modelo proposto pelo município, de acordo com a legislação em Saúde Mental. O CAPS inicialmente dava continuidade ao tratamento psiquiátrico após a alta hospitalar dos egressos da Casa de Saúde Volta Redonda, que não consistia apenas em administração de medicamentos, como no modelo 
anterior, pois era disponibilizado ao paciente um tratamento ampliado, através de "grupo de família"; "grupo bom-dia" (realizado diariamente no café da manha); oficinas: jardinagem, musicoterapia, artesanato, caminhada, vídeo e leitura; grupo musical e assembléia geral, essa última acontecia quinzenalmente, com reuniões para discussão de regras de funcionamento, organização de festas e eventos, entre outros. O CAPS funcionava de 8 às 18 horas, com uma equipe de 12 profissionais: dois psiquiatras, uma enfermeira, quatro psicólogos, duas técnicas de enfermagem, uma secretária, um auxiliar de cozinha e um auxiliar de limpeza. A unidade atendia cerca de 320 usuários nessa época. ${ }^{13}$

O direito de cidadania do paciente psiquiátrico inserido no CAPS era o de identidade; de ter de volta seus documentos e exercitar sua cidadania; de trabalho; de conviver com pessoas; de ir e vir, transitando nos espaços de dentro para fora e viceversa; de receber assistência à saúde norteada pelos preceitos da Reforma Psiquiátrica; de articulações com toda a rede de assistência à saúde do município para sua reinserção social, e atividades que permitiam o resgate da autonomia com ações motivadoras como: oficina de beleza, oficina de sexualidade, oficina de música e lazer entre outras. ${ }^{5}$

De modo a dar prosseguimento a iniciativa da equipe interdisciplinar da CSVR na construção de um espaço legítimo de discussões de direitos de cidadania ao paciente psiquiátrico, foi criada Associação dos Usuários, Familiares e Amigos dos Serviços de Saúde Mental de Volta Redonda (AUFASSAM-VR), que inicialmente se reunia na CSVR com encontros quinzenais. Essa associação tinha como objetivos: desenvolvimento de atividades que buscavam a efetivação dos direitos fundamentais a todos os usuários do serviço de Saúde Mental; garantir a todos os usuários direito a uma vida plena em suas dimensões psicológica, existencial, social e política; assistência à saúde mental como direito de todo cidadão; direito à liberdade, dignidade e ser tratado e ouvido como pessoa humana com seus direitos civis, políticos e sociais. ${ }^{5}$

A AUFASSAM que pretendia ser uma entidade civil, sem fins lucrativos e se fortaleceu, tornando-se instrumento de garantias aos direitos dos pacientes psiquiátricos. Várias experiências de associações de usuários e familiares já foram criadas na lógica de organização de espaços formais fortalecendo a construção da Reforma Psiquiátrica no Brasil, como foi o caso da "Associação Loucos pela Vida" (hospital de Juquerí, SP), "Associação Franco Baságlia" (CAPS Luis Cerqueira, SP), "As- sociação Franco Rotelli" (Santos, SP) e "Associação Cabeça Feita" (hospital Psiquiátrico Jurujuba, Niterói, RJ); entre outras. ${ }^{14}$

Como advento do novo modelo de tratamento em Saúde Mental, usando como dispositivo o CAPS, o paciente estava inserido no convívio familiar. Dessa forma as famílias tiveram que assumir responsabilidades, dispensando cuidados ao seu familiar. A família teve que ter uma maior proximidade com o CAPS, na garantia de continuidade de assistência com atendimento, suporte da equipe interdisciplinar e a poio às dúvidas, medos e incertezas que permeavam a todos que vivenciavam as novas experiências.

A primeira coordenadora do CAPS foi uma enfermeira, que permaneceu nessa função por dois anos (1995-1997). Segundo seu depoimento escrito, sua atuação não se detinha apenas à prática administrativa: minha função foi de gerência da equipe de enfermagem e assistência aos pacientes e familiares..., embora houvesse a atividade gerencial, a minha atuação maior foi no cuidado. Em conjunto com a equipe e usuários, construímos e implementamos a oficina de jardinagem, a caminhada e a oficina de vídeo. O trabalho assistencial era bem planejado e organizado (D6).

A atuação de uma enfermeira na coordenação do primeiro dispositivo extra-hospitalar representava o reconhecimento da equipe interdisciplinar e das autoridades municipais envolvidas com a saúde mental, quanto à competência profissional da mesma para gerenciar o serviço e os cuidados especializados aos doentes com sofrimento mental.

Este estudo se assemelha com outras produções acadêmicas no que se refere ao entendimento de que a desinstitucionalização com conseqüente desconstrução do manicômio e dos paradigmas que o sustentam, é uma das vertentes principais da reforma psiquiátrica, bem como a adoção cresscente de práticas terapêuticas que visam a cidadania do doente mental. Não obstante, este estudo permite conhecer o fenômeno histórico em uma realidade própria, a partir da intervenção de autoridades políco- partidária nas questões relativas à assistência psiquiátrica no município.

\section{CONSIDERAÇÕES FINAIS}

As propostas de reformulação da assistência psiquiátrica e da cultura manicomial das instituições vêm deixando de ser uma atividade marginal, "alternativa", para ocupar um lugar de vanguarda no quadro das políticas de saúde. 
A psiquiatria, a loucura e o destino dos chamados doentes mentais são questões hoje debatidas pela sociedade e deixaram de ser problema de especialistas. Nesse debate, dois temas são centrais: a questão da cidadania do louco e o problema dos modelos assistenciais.

As mudanças na política de Saúde Mental de Volta Redonda exigiu novas posturas de trabalho, novas práticas e atitudes de todos que participavam do processo de implantação da Reforma Psiquiátrica naquele município. Para isso, foi reestruturada toda a equipe de trabalho, no sentido de viabilizar as propostas de mudanças da assistência psiquiátrica, tendo como pilar da proposta, a ressocialização, através da inserção do paciente psiquiátrico na comunidade e do resgate de sua autonomia.

O estudo mostrou que a experiência de Volta Redonda foi se construindo, com dificuldades e enfrentamentos dos desafios. Por ser uma fase de transição, novos saberes e novas práticas se articulavam com as tradicionais (antigas). Também não foi uma experiência isolada, ao contrário, fazia parte de um projeto político partidário mais abrangente, com experiências acumuladas em outros municípios brasileiros.

A equipe de enfermagem encontrada na CSVR se mostrava insuficiente para as novas propostas e foi readequada com a contratação de profissionais que não eram especializados em saúde mental, mas que pareciam se adequar ao perfil da nova proposta de assistência ao paciente psiquiátrico.

Com a implantação da Reforma Psiquiátrica no município de Volta Redonda a equipe de enfermagem teve a oportunidade de conquistar espaços de poder e visibilidade capazes de assegurar a participação da categoria, quando da criação do CAPS para os usuários egressos da CSVR e para os doentes psiquiátricos, em geral, em processo de desinstitucionalização.

A equipe de enfermagem era considerada de grande relevância para o êxito no processo de implantação da Reforma Psiquiátrica no município de Volta Redonda, uma vez que prestava assistência direta e em tempo integral aos doentes psiquiátricos. O investimento político empreendido era grandioso e, portanto, tudo deveria ser feito cuidadosamente para a consagração da nova proposta política para o campo da psiquiatria em Volta Redonda.

Assim, ao tempo em que a enfermagem serviu aos interesses das autoridades responsáveis pela implantação da Reforma Psiquiátrica no município em questão, também obteve ganhos simbólicos, ao aumentar o seu capital científico e profissional nas questões relativas ao novo modelo de assistência ao doente mental. Assim, a atualização do habitus profissional permitiu aos enfermeiros a enunciação do discurso autorizado em enfermagem psiquiátrica, cabendo-lhe o reconhecimento por parte dos demais profissionais da equipe de saúde mental; pelos usuários e suas famílias; pela coordenação do Programa de Saúde Mental; e pela Secretaria Municipal de Saúde. Este reconhecimento oportunizou a presença da enfermagem nos novos dispositivos extra-hospitalares criados, sendo solicitada sua participação em todas as demais atividades previstas na política de saúde mental no município.

\section{REFERÊNCIAS}

1. Gonçalves AM, Sena R. A reforma psiquiátrica no Brasil: contextualização e reflexos sobre o cuidado com o doente mental e na família. Rev Latino-am Enfermagem. 2001 Jan-Mar; 9(2):48-55.

2. Schrank G, Olschowsky A. O centro de atenção psicossocial e as estratégias para inserção da família. Rev Esc Enferm USP. 2008 Jan-Mar; 42(1):127-34

3. Oliveira G.B, Alessi NP. O trabalho de enfermagem em saúde mental: contradições e potencialidades atuais. Rev. Latino-am Enfermagem. 2003 Mai-Jun; 11(3):333-40

4. Waidman MAP, Elsen I, Marcon SS. Possibilidades e limites da teoria de Joyce Travelbee para a construção de uma metodologia de cuidado à família. Rev Eletrônica Enferm [online]. 2008 [acessado 2008 Abr 02]; 8(2). Disponível em http://www.fen.ufg.br/ revista/revista8_2/pdf/v8n2a13.pdf

5. Moraes AEC. Casa de Saúde Volta Redonda como lócus de implantação da reforma psiquiátrica no município de Volta Redonda: a participação da enfermagem (1993 - 1995). [dissertação]. Rio de Janeiro (RJ): Escola de Enfermagem Anna Nery/ UFRJ; 2008.

6. Castro H. História social. In: Cardoso CF, Vainfas $\mathrm{R}$, organizadores. Domínios da História. ensaios de teoria e metodologia. Rio de Janeiro (RJ): Ed. Campos, 1997.

7. Rocha RM. O enfermeiro na equipe interdisciplinar do Centro de Atenção Psicossocial e as possibilidades de cuidar. Texto Contexto Enferm. 2005 Jul-Set; 14(3):350-7.

8. Terra MG, Ribas DL, Sarturi F, Erdmann AL. Saúde mental: do velho ao novo paradigma - uma reflexão. Esc Anna Nery Rev Enferm. 2006 Dez; 10(4):711-7.

9. Bourdieu P. A economia das trocas lingüísticas: o que falar quer dizer. São Paulo (SP): EDUSP, 1999. 
10. Bourdieu P. Os usos sociais da ciência. São Paulo (SP): Editora UNESP, 2004.

11. Cunha MP. O espelho do mundo: Juqueri a história de um asilo. Rio de Janeiro (RJ): Paz e Terra, 1986.

12. Machado SC, Stipp MAC, Oliveira RMP, Moreira MC, Simões LM, Leite JL. Liderança em enfermagem psiquiátrica. Esc Anna Nery Rev Enferm. 2006 Dez; 10(4):730-4
13. Ruiz VS. A Dimensão gestadionária da clínica: a experiência em um serviço de saúde mental [dissertação] Rio de Janeiro (RJ): Universidade do Estado do Rio de Janeiro, Curso de mestrado em Psicologia; 2003.

14. Amarante P. organizador. Loucos pela vida: a trajetória da reforma psiquiátrica no Brasil. Rio de Janeiro (RJ): Fiocruz; 1995. 